\title{
Métodos e Fases da Avaliação de Cargos
}

\section{Carlos José Malferrari*}

1. Definição, Importancia e Limitações da Ava. liação. 2. Fases da Avaliação de Cargos. 3. Métodos de Avaliação de Cargos. 4. A Avaliação de Cargos na Estrutura da Emprêsa.

A avaliação de cargos constitui parte fundamental do departamento da emprêsa que está encarregado da administração de salários, ao lado do levantamento, análise e descrição de cargos que tornam possível a própria avaliação das pesquisas e estudos salariais e dos planos de incentivos.

A administração de salários, por sua vez, ocupa um dos lugares mais importantes na administração das emprêsas, quer exista formalmente, com encarregados e técnicos que tratam do assunto de modo sistemático, quer informalmente, quando inúmeras pessoas se preocupam com os salários e ordenados pagos, mas pouco podem fazer por não saberem exatamente o que fazer. $O$ fato é que as diretrizes nesse setor variam profundamente de uma emprêsa para outra, e, mesmo dentro de uma emprêsa, de uma ocasião para outra. Essa incerteza afeta, a custos não pequenos, tôda a organização, seu pessoal e suas operações. É evidente, então, que um problema básico de administração será estabelecer uma administração salarial de fato.

* Vice-diretor da Escola de Administração de Emprêsas de São Paulo, da Fundação Getúlio Vargas e professor-adjunto do Departamento de Administração Geral e Relações Industriais da mesma escola.

R. Adm. Emp., Rio de Janeiro, 10(2): 11-37, jul./set. 1970 
Ainda hoje não é possível contar com precisão científica para remunerar corretamente o trabalho, mas isso não significa que os administradores estejam totalmente desamparados nesse sentido. Já é viável, atualmente, uma administração salarial sistemática que aperfeiçoe as decisões relativas a pagamentos, tendo a vantagem de tornar compreensível, a todos os afetados, o processo de estabelecer salários.

Os níveis de salários pagos pela emprêsa podem ser controlados, até certo ponto, por diretrizes estabelecidas pela diretoria, através de uma administração formalizada de salários que tenha à sua disposição modernas técnicas de pesquisa, de análise e de avaliação. Tanto os empregados quanto a diretoria só têm a ganhar com o funcionamento de um sistema de remuneração. Ele afetará os salários pagos, facilitará o recrutamento e. a manutenção de mão-de-obra qualificada e terá efeitos salutares sôbre a eficiência e o ambiente de trabalho da organização.

O departamento encarregado da administração salarial deve abranger, em linhas gerais, as seguintes funções: a) levantamento, análise, descrição e avaliação de cargos; b) pesquisas. e estudos salariais; c) incentivos; e também estar ligado à d) avaliação do desempenho dos empregados.

Neste artigo será abordado apenas o item a; embora tôdas as funções acima sejam indispensáveis ao departamento, elas são, em geral, tratadas separadamente.

\section{Definição, Importância e Limitaçroes da Avaliação}

A avaliação de cargos pode ser considerada como um conjunto. de procedimentos sistemáticos utilizados para medir o valor e a importância dos cargos, com a finalidade de estabelecer diferenciais de salários, de modo que êstes correspondam, tanto quanto possível, ao valor do trabalho.

A avaliação de cargos é essencialmente um processo de aferição. Fatôres que se consideram relevantes para a determinação. do valor dos cargos são medidos de acôrdo com padrões, arbitràriamente escolhidos. As proporções de cada fator são so- 
madas para cada cargo e os totais são convertidos em valôres monetários. Assim, a cada cargo corresponde uma certa quantia em cruzeiros, em relação bem definida com outros cargos, pois todos foram medidos com os mesmos padrões.

Em síntese, a avaliação compara as características de cada cargo com outros cargos, preocupando-se, portanto, mais com os niveis relativos de salários, uns em relação a outros, do que com o próprio nível absoluto de cada um. Esse fato se relaciona de certa forma com constatações feitas por estudiosos do assunto, de que os empregados, alem de compensação financeira em retribuição ao seu trabalho, desejam satisfação pessoal, tratamento digno, segurança e posição apropriada em relação aos seus colegas.

Por outro lado, o que é muito importante, a avaliação de cargos, como o próprio nome indica, não se refere à avaliação do desempenho das pessoas nos cargos, mas dos cargos em si mesmos. A premissa fundamental é, então, o próprio cargo, com os deveres e responsabilidades, qualificações e esforços exigidos, condições peculiares, etc.

Apesar de todos os benefícios dessa avaliação, ela está sujeita a várias limitações. Feita pela primeira vez em 1924, em pleno vigor do entusiasmo provocado pela administração científica de Taylor, Gantt e outros, ela ainda está longe de ser científica. Há muito julgamento pessoal em cada uma de suas fases, o que não foi eliminado em nenhum dos métodos existentes. Ela não se relaciona com a oferta e a procura, o transporte, as distâncias, e ignora as relações humanas do trabalho. Além disso, alguns cargos, com o mesmo conteúdo, podem atrair diferentemente os indivíduos; cargos muito especializados e peculiares a uma firma só têm valor para ela, e cargos de continuidade diferente, isto é, de serviços empreitados, dificilmente podem ser comparados com outros.

Essas limitações são reais. Elas podem ser e estão sendo reduzidas pela experiência e aperfeiçoamento dos métodos de avaliação, mas jamais serão totalmente eliminadas, pois o processo de avaliação é sempre executado por sêres humanos, e sujeito a tôdas as vantagens e desvantagens decorrentes disso. 
A necessidade da avaliação de cargos surge quase sempre depois que a emprêsa atingiu um certo tamanho e que mestres, chefes e gerentes não têm mais possibilidade de, simplesmente com seus conhecimentos, experiência e bom senso, estabelecer remunerações consistentes com os valôres dos cargos. Dado o crescimento da emprêsa, os diversos cargos sofrem modificações em seus objetivos e procedimentos; por alterações nelles introduzidas pelos seus diversos ocupantes e pelo simples aumento de seu número, os cargos tornam-se diferentes, no decorrer do tempo, quanto a deveres e responsabilidades, qualificações, condições de trabalho e remuneração. Isso leva frequientemente a situações de insatisfação generalizada.

\section{Fases da Avaliação de Cargos}

O valor da avaliação de cargos mede-se pelo que valem os fatos nos quais ela se baseia. Esta afirmativa tem em vista realçar a importancia do papel do levantamento, da análise e da descrição de cargos que, nas fases iniciais do processo de avaliação, respectivamente, coletam, examinam e relatam os dados colhidos sóbre os mesmos.

Convém desde já estabelecer a terminologia, definindo algumas das fases básicas da avaliação de cargos. E o que fazemos abaixo.

- Levantamento de cargos - compilação metódica de informações, incluindo descrições preliminares. E comum incluir esta fase na Análise de Cargos, mas é melhor destacá-la pois é nela que todo o processo se baseia.

- Análise de cargos - estudo crítico das informações sôbre os cargos obtidos na fase anterior.

- Descrição de cargos - relatório escrito, preparado a partir da análise, em geral constando de manuais.

- Especificação de cargos - estipulação das exigências e qualificações pessoais necessárias ao desempenho do cargo.

- Cargo - conjunto de funções, deveres, responsabilidades e condições de trabalho características. 
- Emprêgo - cargo preenchido por uma pessoa específica, isto é, o que dá caráter pessoal ao cargo.

\subsection{LEVANTAMENTO E ANALISE}

O levantamento de informações e de outros dados relativos aos cargos e a análise posterior dos mesmos têm papel capital no programa total da avaliação de cargos e de merecimento. Além disso, êsse estudo é indispensável na seleção, nas transferências, nas promoções e no treinamento de pessoal, pelos elementos que fornece sôbre deveres do cargo, duração da jornada, condições de trabalho, capasidade e prática requeridos dosocupantes do cargo, relações entre os cargos, etc.

Alguns tendem a confundir em parte a análise de cargos com o estudo de movimentos e tempos segundo os princípios da Administração Científica. Entretanto, as finalidades de ambos são bem diferentes. $O$ estudo de movimentos e tempos, feito em geral por cronoanalistas e outros técnicos, tem por finalidade a eliminação de movimentos supérfluos, a simplificação e melhoria da execução do trabalho e a análise da execução do trabalho, enfim, a racionalização. Já a análise de cargos é muito mais. geral, não entrando nesses pormenores, preocupando-se mais com os deveres, responsabilidades e condições de trabalho, conforme já vimos.

Os dados relativos a cada cargo podem ser coletados por meio de questionários impressos, entrevistas, observação ou peła combinação dêsses três métodos. Os questionários, mais usados para cargos de escritório, devem ser uniformes, permitindo respostas fáceis. As entrevistas devem ser esquematizadas. para que os entrevistadores não sigam por caminhos diferentes. A observação, em geral, tem caráter acessório. Em qualquer dos métodos, tanto o ocupante do cargo quanto o seu superior imediato devem prestar informaçóes relativas ao cargo, para melhor conferência. A prática tem mostrado, para surprêsa: de muitos, a grande diferença que pode existir entre a descrição que um ocupante faz de seu cargo e aquilo que o superior acha que nêle deveria ser realizado.

Os analistas, além de saber entrevistar, escrever com facilidade e sem rebuscamentos, devem ter capacidade de trabalhar objetivamente, sem a necessidade de uma supervisão constante. 
Poucas emprêsas incluem todos os cargos em seu programa de avaliação. $\mathrm{Na}$ maioria das vêzes, são incluídos sòmente os cargos de fábrica ou de escritório; em alguns casos os de vendas e, pouquíssimas vêzes, os de direção. A primeira vista poderia parecer que nenhum cargo deveria ser excluído, mas a impossibilidade de contar com o pessoal necessário para uma operação de tal envergadura, aliada aos fatôres tempo e dinheiro, tendem a limitar o programa de avaliação para cargos mais rotineiros aos que existem em maior número, eliminando-se os de chefia, os referentes às profissões liberais e essencialmente os técnicos de alto nível.

\subsection{DESCRIÇAO E ESPECIFICAÇAO}

Os informes coletados sôbre o cargo, depois de cuidadosamente analisados, devem ser escritos, da maneira mais clara possível, em formulários impressos que, no seu conjunto, constituirão) manual de descrição de cargos. Esses impressos variam muito de forma, mas nêles sempre se encontram como partes essenciais:

a) cabeçalho - com o título do cargo, código do cargo, local de trabalho, número de empregados no cargo, departamento a que pertence, data da coleta de dados, às vêzes, o nome do mestre, mas nunca o do ocupante do cargo.

b) sumário - um curto parágrafo com uma descrição abreviada do cargo e sua finalidade.

c) deveres e responsabilidades - relação sucinta do que se espera do cargo, da sua importância para a emprêsa, etc.

d) especificaçóes - exigências relativas à experiência e características necessárias, instrução e condições de trabalho.

e) diversos - materiais, instrumentos e equipamentos usados, duração, fluxograma do trabalho, posição na organização, etc.

Baseados nessas descrições, impressas em formulários e contidas em manuais, os membros da comissão de avaliação devem 
efetuar os seus julgamentos sôbre o que é importante em cada um dos cargos, quais os fatôres que permitem distinguir uns dos outros, quantos pontos atribuir aos fatôres, etc. Jamais teremos uma avaliação bem feita se as fases anteriores de levantamento, análise e descrição não forem muito bem elaboradas.

\subsection{APLICAÇÃO A CARGOS EXECUTIVOS}

As análises, descrições e especificações acima discutidas são normalmente aplicáveis a quaisquer cargos, porém sua aplicação para cargos executivos de nível elevado não tem correspondido às expectativas, e muita coisa ainda há por fazer.

É duvidosa a validade de especificações abrangendo personalidade, podêres, autoridade, responsabilidade e o que os executivos fazem ou deveriam fazer. O método adequado para descrever posições executivas deve levar em conta a complexidade e flexibilidade das mesmas, pois elas não poderão ser bem descritas por meio de extensas listas de atividades e responsabilidades específicas. As posições executivas devem ser consideradas sob critério bem mais amplo, de modo a incluir características menos tangiveis do cargo, como exigências pessoais e restrições sociais. Além disso, é comum que posições executivas não constituam, na realidade, um cargo único, mas uma verdadeira combinação de cargos, com tôdas as implicações resultantes de uma multiplicidade de deveres e responsabilidades em conflito. ${ }^{1}$

\section{Métodos de Avaliação de Cargos}

Embora cada emprêsa, considerando as suas características próprias, possa e deva adotar procedimentos que lhe sejam mais convenientes - o que acarreta a existência de uma infinidade de métodos de avaliação de cargos - é possível distinguir e agrupar pelo menos quatro dentre êsses métodos; os mais utilizados, isoladamente ou combinados entre si das maneiras as mais diversas, são:

1 Para conhecer novos critérios, que permitam aperfeiçoar 0 difícil processo de analisar e descrever cargos executivos, é interessante ler o artigo Job Descriptions for Executives, de JoHN K. HEMPHILL, na Harvard Business Review, set./out. de 1959, p. 55 a 67. 
1. Escalonamento simples de cargos.

2. Classificação predeterminada.

3. Comparação de fatôres.

4. Método de pontos.

Qualquer um dêles exige sistematização e pressupõe a existência de uma organização que tenha, como objetivos, mais produtividade e eficiência de funcionamento.

\subsection{METODO DE ESCALONAMENTO SIMPLES}

Nesse caso, os cargos a avaliar devem ser selecionados em seqüência, crescente ou decrescente, do seu valor relativo, com bases nos julgamentos feitos pela comissão e tomando-se a média da classificação dada pelos membros da mesma. As comparações, em geral, baseiam-se nos cargos inteiros, não se dividindo nada em fatôres ou subfatôres de espécie alguma.

Descrições de cargos seriam imprescindíveis neste método, mesmo que fôssem breves e genéricas; mas, na realidade, a classificação quase sempre é feita mentalmente pelos que conhecem bem os cargos, confiando na memória.

Quando os cargos são muitos, deve-se começar por um departamento, passando-se depois para uma análise interdepartamental. Independentemente do número de cargos a avaliar, escolhem-se cargos-chave, importantes, bem conhecidos por todos, fàcilmente comparáveis com outros e identificáveis no organograma da emprêsa. Dêstes cargos, parte-se, então, para o arrolamento dos demais.

Cada membro da comissão poderá escalonar os cargos como desejar, mas é sempre melhor que se estabeleça uma uniformização de critérios; por exemplo, todos os avaliadores tomam os cargos, dois a dois, para obter o ordenamento final. Além disso, as reavaliações favorecem a precisão dos resultados finais.

Este método é muito simples e rápido, mas são várias as suas deficiências: a subjetividade dos avaliadores, a dificuldade de separar os cargos dos seus ocupantes, a tendência de acompanhar o que está feito. A falta de experiência dos avaliadores é 
também prejudicial quando vários departamentos estão envolvidos.

Para tornar o método de escalonamento mais adequado é preciso, então, que se constitua uma comissão capaz, e que se preparem cartões com descrições de cargos, mesmo sumárias, e que se escolham os fatôres usuais para definição dos cargos, tais como habilidade e esfôrço necessários, as responsabilidades exigidas e as condições de trabalho. Em outras palavras, que se utilizem aqui certas características dos métodos de avaliação mais complexos, que veremos em seguida.

Um exemplo fíctício será útil para esclarecer melhor o método de escalonamento de cargos: suponhamos uma comissão constituída dos senhores A, B, C, D, E, escolhidos entre os assessôres de pessoal e mestres, sendo que os cargos de ferramenteiro, torneiro, montador, maquinista, servente e limpador vão ser avaliados. Depois de algumas reunióes para entrosamento de idéias, discussão dos cargos, uniformização dos critérios de julgamento e esclarecimento das dúvidas existentes, cada um dos avaliadores classificará os cargos em ordem de importância. Em seguida, obtém-se a média das classificações atribuindo-se às mesmas valôres em cruzeiros, observando-se sua ordem, conforme consta do Quadro 1.

Quadro 1: Método de Escalonamento Simples Classificação de Cargos

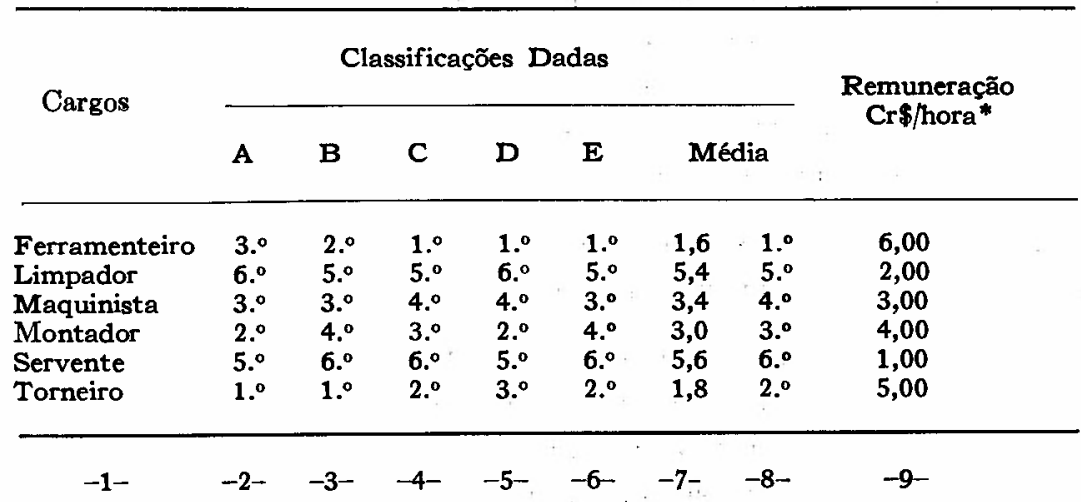

* Os níveis de remuneração por hora não șão baseados em dados rea is levantados, servindo apenas para exemplo; mesmo a seqüência pode variar de uma emprêsa para outra. Isso se aplica a todos os casos onde aparecem remunerações de cargos. 
Na coluna 7, colocam-se as médias das colocações dos cargos feitas pelos cinco avaliadores e na coluna 8 as classificações já acertadas, às quais serão atribuídos os níveis salariais da coluna 9. Êstes níveis salariais são conhecidos por serem já adotados na firma ou por terem sido obtidos por uma pesquisa salarial.

\subsection{MÉTODO DE CLASSIFICAÇÃO PREDETERMINADA}

Sob determinados aspectos, êste método é um aperfeiçoamento do anterior; é também fácil de compreender, rápido, não precisando de especialistas para o seu emprêgo. É mais preciso do que o método do escalonamento, mas apresenta as mesmas deficiências: depende em grande escala da subjetividade, sendo muito prejudicado por avaliadores mal orientados, etc.

Para sua utilização, estabelecem-se inicialmente, baseadas em observações e experiências, inúmeras situações de trabalho, definidas por classes ou grupos, descritas com a maior pormenorização e cuidados possíveis, incluindo requisitos necessários para o desempenho das funções. Em seguida, procura-se encaixar os cargos que estão sendo avaliados individualmente, de acôrdo com as suas características, dentro de cada uma dessas classes, para as quais já se poderão ter determinado os salários correspondentes.

As decisões devem ser feitas antes para os agrupamentos maiores: escritório, fábrica, vendas e assim por diante. Consideram-se os mesmos elementos básicos para todos, utilizando-se muitos exemplos. Dentro de cada grupo procura-se determinar ainda os diversos níveis de dificuldades.

Suponhamos, por exemplo, que as seguintes classes tenham sido definidas: (caso de serviços administrativos)

Classe I. Não qualificada - de $\mathrm{Cr} \$ 150,00$ a $\mathrm{Cr} \$ 300,00$ mensais. Confiança, boa aparência, expediente, instrução primária, não precisa de treinamento, etc. Ex.: mensageiros, office-boys, escriturários.

Classe II. Qualificada - de $\operatorname{Cr} \$ 300,00$ a $\mathrm{Cr} \$ 800,00$ mensais. Confiança, treinamento manual, instrução secundá- 
ria, destreza, maior grau de responsabilidade, conhecimento de pormenores.

Ex.: taquígrafas, secretárias.

Classe III. Interpretativa - de $\mathrm{Cr} \$ 800,00$ a $\mathrm{Cr} \$ 1.500,00$ mensais. Capacidade para classificar, organizar, analisar; responsável por resultados.

Ex.: correspondentes, assistentes.

Classe IV. Criativa - Cr $\$ 1.500,00$ a $\mathrm{Cr} \$ 3.000,00$ mensais. Inovação técnica, variada, pormenores fora de rotina.

Ex.: engenheiros, vendedores, projetistas.

Classe V. Administrativa-executiva - de Cr $\$ 3.000,00$ a .. Cr\$ 5.000,00 mensais. Maiores responsabilidades, controlam trabalho de outros.

Ex.: superintendentes, gerentes, chefes.

$\hat{E}$ evidente que tais classes ou grupos podem ser mais explícitos e exemplificados. Em geral, tanto êste método quanto o anterior devem ser restritos às emprêsas de pequeno porte, aos cargos mais simples e em pequeno número, principalmente se os recursos são reduzidos e o tempo é pouco. Mas o uso de qualquer um dêles, como um sintoma do interêsse manifestado pela emprêsa em adotar uma politica salarial bem mais definida, pelas discussões e estudos que provoca, já resulta em um grande benefício para a organização.

\subsection{MÉTODO DE COMPARAÇÃO DE FATORES}

Como em todos os métodos aperfeiçoados, êste deve passar inicialmente pelas mesmas etapas de coleta, análise, descrição de cargos e designação de comissões avaliadoras. Sua primeira aplicação foi feita por Benge em 1926, e na extensão de sua aplicação só é ultrapassado pelo método de pontos.

Determinam-se, em primeiro lugar, os fatôres que irão ser utilizados no processo. Esses fatôres, que permitem comparar os diversos cargos, variam de uma para outra e até mesmo dentro de uma emprêsa. Entretanto, na quase totalidade dos casos, podem ser reduzidos a quatro grandes grupos: habilidade, es- 
fôrço, responsabilidade e condições de trabalho. Cada um dêstes fatôres pode ser subdividido, como por exemplo: habilidade experiência, instrução, iniciativa, engenhosidade; esfôrço - físico, mental, visual; responsabilidade - por pessoas, máquinas, valôres, produtos, segurança; condições de trabalho - higiene, periculosidade.

Mesmo que haja essas subdivisões dos fatôres básicos, êles devem manter-se amplos, flexíveis e sem sobreposição de uns aos outros.

Em segundo lugar, selecionam-se e descrevem-se, com todo o cuidado, os cargos-chave, isto é, os que servirão de padrões para todos os demais. Cêrca de 10 a 25 cargos, conforme o tamanho da organização, podem ser escolhidos, desde que: a) sejam bem representativos, b) estáveis no organograma, c) conhecidos por muitos, d) fáceis de definir, e) correspondentes a vários níveis de salários e f) cujos valôres monetários sejam considerados justos e razoáveis, tanto dentro quanto fora da emprêsa.

$\mathrm{Na}$ terceira etapa, os diversos membros da comissão de salários (A, B, C, D e E), depois de bem estudadas as descrições dos cargos-chave, ordenam-nos isoladamente para cada um dos fatôres escolhidos (como no primeiro método - escalonamento simples) preparando tabelas com as médias dos analistas para cada fator, o que dá a classificação dos cargos, conforme os Quadros 2 e 3. Essse escalonamento costuma ser feito mais de uma vez, para se obterem melhores resultados.

Quadro 2: Método de Comparação de Fatôres Classificação Conforme Habilidade (fator I)

\begin{tabular}{|c|c|c|c|c|c|c|c|}
\hline \multirow{2}{*}{ Cargo } & \multicolumn{5}{|c|}{ Classificaçc̃es dadas } & \multicolumn{2}{|c|}{ Médias } \\
\hline & $\mathbf{A}$ & $\mathbf{B}$ & C & $\mathbf{D}$ & $\mathbf{E}$ & Obtidas & Acertadas \\
\hline $\begin{array}{l}\text { Ferramenteiro } \\
\text { Limpador } \\
\text { Maquinista } \\
\text { Montad or } \\
\text { Servente } \\
\text { Torneiro }\end{array}$ & $\begin{array}{l}10^{\circ} \\
50^{\circ} \\
3 .^{\circ} \\
4 .^{\circ} \\
60^{\circ} \\
2 .^{\circ}\end{array}$ & $\begin{array}{l}2 .^{\circ} \\
6 .^{\circ} \\
4 .^{\circ} \\
3 .^{\circ} \\
5 .^{\circ} \\
10^{\circ}\end{array}$ & $\begin{array}{l}1.0^{\circ} \\
50^{\circ} \\
4 .^{\circ} \\
3 .^{\circ} \\
60^{\circ} \\
2 .^{\circ}\end{array}$ & $\begin{array}{l}1.0 \\
5 . \circ \\
2.0 \\
4 .^{\circ} \\
6 .^{\circ} \\
3.0\end{array}$ & $\begin{array}{l}2.0^{\circ} \\
6 .^{\circ} \\
3.0^{\circ} \\
4 .^{\circ} \\
5 .^{\circ} \\
1 .^{\circ}\end{array}$ & $\begin{array}{l}1,4 \\
5,4 \\
3,2 \\
3,6 \\
5,6 \\
1,8\end{array}$ & $\begin{array}{l}1.0 \\
5 . \circ \\
3.0^{\circ} \\
4 .^{\circ} \\
6.0^{\circ} \\
2.0^{\circ}\end{array}$ \\
\hline
\end{tabular}


Repete-se, para cada um dos outros três fatôres, o que foi feito com o fator habilidade e levam-se os resultados da última coluna, em cada caso, para o Quadro 3.

Quadro 3: Métodos de Comparação de Fatôres Médias das Classificações por Fator

\begin{tabular}{|c|c|c|c|c|}
\hline \multirow{2}{*}{ Cargo } & \multicolumn{4}{|c|}{ Fatôres } \\
\hline & Habilidade & Esfôrço & $\begin{array}{c}\text { Responsa- } \\
\text { bilidade }\end{array}$ & $\begin{array}{l}\text { Condições } \\
\text { de Trabalho }\end{array}$ \\
\hline Ferramenteiro & $1 .^{\circ}$ & $30^{\circ}$ & $2 .^{\circ}$ & $5 .^{\circ}$ \\
\hline Limpador & 5.0 & $60^{\circ}$ & 5.0 & $10^{\circ}$ \\
\hline Maquinista & $3 .^{\circ}$ & $20^{\circ}$ & $4 .^{\circ}$ & $60^{\circ}$ \\
\hline Montador & $4 .^{\circ}$ & $10^{\circ}$ & $10^{\circ}$ & $40^{\circ}$ \\
\hline Servente & $6 .^{\circ}$ & $4 .^{\circ}$ & $6 .^{\circ}$ & $3 .^{\circ}$ \\
\hline Torneiro & $2 .^{\circ}$ & $5.0^{\circ}$ & $3 .^{\circ}$ & $2 .^{\circ}$ \\
\hline
\end{tabular}

A quarta etapa, a mais delicada de todo o método, consiste em dividir arbitràriamente, sem relacionar com o Quadro 3, o salário de cada um dos cargos-chave, o que já era conhecido, pelos diversos fatôres adotados. Essa operação deve ser feita mais de uma vez. Comparam-se os resultados, fazem-se as verificações e discutem-se as divergências. Daí resulta o Quadro 4.

Exemplificando: dividem-se os $\operatorname{Cr} \$ 6,00 /$ hora do ferramenteiro em quatro partes, de acôrdo com o que seria devido a cada fator; no caso em questão, resultaram $\operatorname{Cr} \$ 3,00$ para habilidade, $\mathrm{Cr} \$ 0,40$ pelo esfôrço, $\mathrm{Cr} \$ 1,50$ devido à responsabilidade, e .. $\mathrm{Cr} \$ 1,10$ correspondendo às condições de trabalho. Repete-se o parcelamento do salário de cada um dos cargos-chave pelos diferentes fatôres, como foi feito para o cargo do ferramenteiro, e determina-se então a colocação das diversas quantias dentro de cada fator. Completa-se assim o Quadro 4.

A fim de verificar se existem variações muito grandes na comparação entre os cargos-chave por classificação de fatôres (Quadro 3) e por quantias distribuídas pelos fatôres (Quadro 4) pode-se (mas, não é necessário) construir o Quadro 5. 


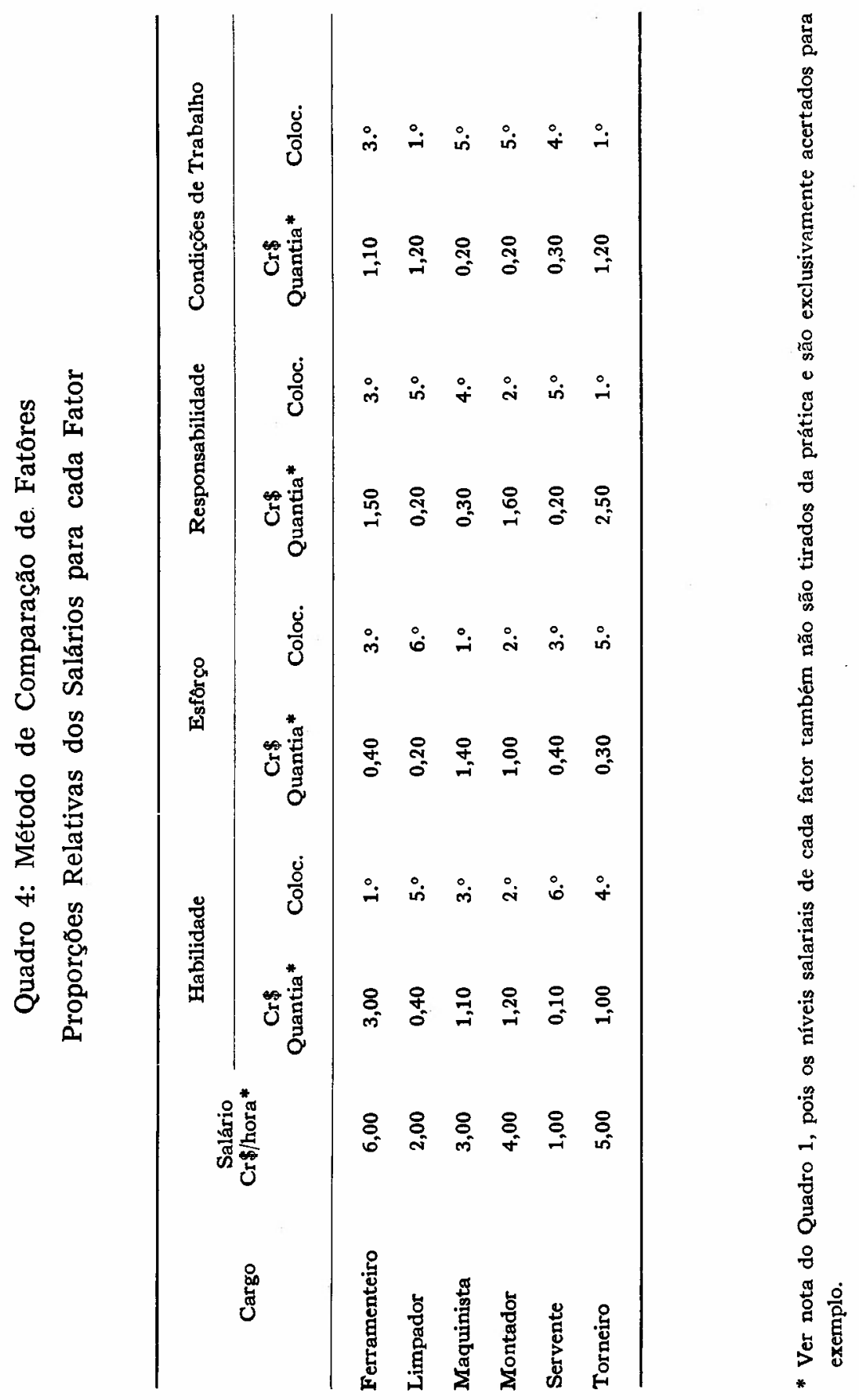


Quadro 5: (De Verificação) - Método de Comparação de Fatôres Comparação das Classificações por Fator e por Quantias

\begin{tabular}{|c|c|c|c|c|c|c|c|c|}
\hline \multirow{2}{*}{ Cargo } & \multicolumn{2}{|c|}{ Habilidade } & \multicolumn{2}{|c|}{ Esforço } & \multicolumn{2}{|c|}{$\begin{array}{c}\text { Responsa- } \\
\text { bilidade }\end{array}$} & \multicolumn{2}{|c|}{$\begin{array}{c}\text { Condições de } \\
\text { trabalho }\end{array}$} \\
\hline & $\begin{array}{l}\text { Coloc. } \\
\text { Q. III }\end{array}$ & $\begin{array}{l}\text { Coloc. } \\
\text { Q. IV }\end{array}$ & $\begin{array}{l}\text { Coloc. } \\
\text { Q. III }\end{array}$ & $\begin{array}{l}\text { Coloc. } \\
\text { Q. IV }\end{array}$ & $\begin{array}{l}\text { Coloc. } \\
\text { Q. III }\end{array}$ & $\begin{array}{l}\text { Coloc. } \\
\text { Q. IV }\end{array}$ & $\begin{array}{l}\text { Coloc. } \\
\text { Q. III }\end{array}$ & $\begin{array}{l}\text { Coloc. } \\
\text { Q. IV }\end{array}$ \\
\hline Ferramenteiro & $1 .^{\circ}$ & $10^{\circ}$ & $30^{\circ}$ & $3 .^{\circ}$ & $2 .^{\circ}$ & $3 .^{\circ}$ & $5 .^{\circ}$ & $3 .^{\circ}$ \\
\hline Limpador & $5 .^{\circ}$ & $5 .^{\circ}$ & $6 .^{\circ}$ & $60^{\circ}$ & $5 .^{\circ}$ & $5 .^{\circ}$ & $1 .^{\circ}$ & $1 .^{\circ}$ \\
\hline Maquinista & $3 .^{\circ}$ & $3 .^{\circ}$ & $2 .^{\circ}$ & $1 .^{\circ}$ & $4 .^{\circ}$ & $4 .^{\circ}$ & $6 .^{\circ}$ & $5 .^{\circ}$ \\
\hline Montador & $4 .^{\circ}$ & $* 2 .^{\circ}$ & $1 .^{\circ}$ & $2 .^{\circ}$ & $1 .^{\circ}$ & $20^{\circ}$ & $4 .^{\circ}$ & $5 .^{\circ}$ \\
\hline Servente & $6 .^{\circ}$ & $6 .^{\circ}$ & $4 .^{\circ}$ & $3 .^{\circ}$ & $6 .^{\circ}$ & $5 .^{\circ}$ & $3 .^{\circ}$ & $4 .^{\circ}$ \\
\hline Torneiro & $20^{\circ}$ & $* 4$. & $5 .^{\circ}$ & $5 .^{\circ}$ & $3 .^{\circ}$ & $* 1 .^{\circ}$ & $2 .^{\circ}$ & $10^{\circ}$ \\
\hline
\end{tabular}

Se considerarmos que, na classificação, diferenças de duas colocações* merecem reexame das avaliações, o Quadro 5 terá servido para constatar que houve quatro casos que devem ser verificados.

Não havendo falhas ou corrigidas aquelas do Quadro 4 ( $4^{\text {a }}$ fase), passa-se diretamente ao Quadro 6, que sumariza a $5^{\text {a }}$ fase do método. Esta consiste em estabelecer uma escala de comparação, na qual se colocam os seis cargos-chave, divididas as respectivas remunerações de acôrdo com os quatro fatôres escolhidos. Os cargos, cujas divergências não foram solucionadas, são eliminados dessa escala. Em seguida, acrescentam-se à tabela os demais cargos, comparando-os com os cargos-chave em cada fator. Para saber a remuneração total de um determinado cargo, somam-se as quantias que constam de cada fator.

Exemplificando: Suponhamos o cargo de carpinteiro. Em habilidade, estaria entre o ferramenteiro e o montador, pouco acima dêste, portanto $\operatorname{Cr} \$ 1,50$; em esfôrço estaria entre o maquinista e o montador, portanto $\mathrm{Cr} \$ 1,20$; em responsabilidade, $\mathrm{Cr} \$$ 0,50; em condições de trabalho, $\mathrm{Cr} \$ 0,90$; numa remuneração total de $\mathrm{Cr} \$ 4,10$. Constata-se que não só o cargo foi bem definido quanto aos diversos fatôres, como também se chegou à atribuição de seu valor monetário. 


\section{Quadro 6: Método de Comparação de Fatôres Escala Comparativa de Cargos}

\begin{tabular}{|c|c|c|c|c|}
\hline $\begin{array}{l}\text { Quantias em } \\
\text { Cr } \$ / \text { hora }\end{array}$ & Habilidade & Esfôrço & $\begin{array}{c}\text { Responsa- } \\
\text { bilidade }\end{array}$ & $\begin{array}{c}\text { Condições de } \\
\text { Trabalho }\end{array}$ \\
\hline 3,00 & Ferramenteiro & & & \\
\hline \multicolumn{5}{|l|}{2,80} \\
\hline \multicolumn{5}{|l|}{2,70} \\
\hline \multicolumn{5}{|l|}{2,60} \\
\hline 2,50 & & & Torneiro & \\
\hline \multicolumn{5}{|l|}{2,40} \\
\hline \multicolumn{5}{|l|}{2,30} \\
\hline \multicolumn{5}{|l|}{2,20} \\
\hline \multicolumn{5}{|l|}{2,10} \\
\hline \multicolumn{5}{|l|}{2,00} \\
\hline \multicolumn{5}{|l|}{1,90} \\
\hline \multicolumn{5}{|l|}{1,80} \\
\hline \multicolumn{5}{|l|}{1,70} \\
\hline \multicolumn{2}{|l|}{1,60} & \multicolumn{3}{|c|}{ Montador } \\
\hline 1,50 & Carpinteiro & \multicolumn{3}{|c|}{ Ferramenteiro } \\
\hline 1,40 & & Maquinista & & \\
\hline \multicolumn{5}{|l|}{1,30} \\
\hline 1,20 & Montador & Carpinteiro & & $\begin{array}{l}\text { Torneiro } \\
\text { Limpador }\end{array}$ \\
\hline 1,10 & Maquinista & & & Ferramenteiro \\
\hline 1,00 & Torneiro & Montador & & \\
\hline 0,90 & & & & Carpinteiro \\
\hline \multicolumn{5}{|l|}{0,80} \\
\hline \multicolumn{5}{|l|}{0,70} \\
\hline \multicolumn{5}{|l|}{0,60} \\
\hline 0,50 & & & Carpinteiro & \\
\hline 0,40 & Limpador & $\begin{array}{l}\text { Ferramenteiro } \\
\text { Servente }\end{array}$ & & \\
\hline 0,30 & & Torneiro & Maquinista & Servente \\
\hline 0,20 & & Limpador & $\begin{array}{l}\text { Servente } \\
\text { Limpador }\end{array}$ & $\begin{array}{l}\text { Maquinista } \\
\text { Montador }\end{array}$ \\
\hline 0,10 & Servente & & & \\
\hline 0,00 & & & & \\
\hline
\end{tabular}


Comparado com os métodos anteriores, êste possui uma vantagem essencial, favorecendo maior precisão na avaliação, pois, enquanto anteriormente os cargos eram julgados in totum, agora há julgamento para parcelas menores dos mesmos, permitindo maior objetividade. Com os fatôres reduzidos, sua aplicação torna-se também mais flexível. Outro ponto favorável é que a comparação de cargo com cargo, na escala, é mais viável do que a de cargo com uma definição qualquer. Uma vez estabelecida a escala, os mais diferentes cargos podem ser avaliados sem maiores problemas (de escritório, executivos, criativos, manuais, supervisão, etc.). Tais cargos são sempre comparados para se determinar os fatôres de um em relação ao outro, e não é preciso chegar-se a nenhum valor absoluto, seja monetário ou de tempo. Em resumo, êste método é essencialmente uma classificação, mas uma classificação aperfeiçoada pela utilização de diversos fatôres componentes do cargo.

Contra o método, pode-se alegar que as dificuldades de se estabelecer a escala de comparação arbitrária limitam o seu uso. Além disso, o método é demorado, requer avaliadores muito bem treinados e, o que é óbvio, não é fácil explicá-lo aos que serão avaliados. Essas limitações jamais desaparecerão de todo, mas podem ser reduzidas a um mínimo que pouco afetará os resultados.

Finalmente, convém lembrar que a escala de comparação, base de todo o método, pode ser estabelecida de várias maneiras. $O$ processo adotado acima segue as linhas gerais do chamado Plano Benge, que faz parte do primeiro Método de Comparação de $\mathrm{Fa}$ tôres que surgiu. Entretanto, outros planos existem, como o Plano de Pontos de Hay, que se utiliza de um sistema de pontos para construir a escala de comparação; o Plano Percentual de Turner, onde se atribui $100 \%$ ao fator mais bem classificado; o Plano Comparativo de Hay, muito simples, pelo qual se comparam os fatôres dos cargos com fatôres de cargos já conhecidos de outras emprêsas. Há outros ainda, pois cada organização procura escolher os seus fatôres da maneira mais adequada às suas próprias características. ${ }^{2}$

2 Todos êsses planos estão claramente descritos no artigo de HAY, EDW,ARD N. Four Methods of Establishing Scales in Factor Comparison Job Evaluation, The AMA Handbook of Wage and Salary Administration. AMA, Nova Iorque, 1950 , p. 56 a 65. 


\subsection{METODOS DE PONTOS}

Este é o método mais usado para a avaliação de cargos, pois fornece bons resultados sem despesas ou esforços excessívos. Avalia-os por meio de padrões, ou seja, fatôres comuns a todos os cargos, como no processo de comparação de fatôres. No método de pontos, porém, os cargos recebem pontos na proporçăo em que nêles existam os fatôres escolhidos pela comissão. Somam-se os resultados das várias medidas, em pontos, chegando-se a um valor quantitativo para cada cargo, que será convertido em cruzeiros.

Esse valor quantitativo é seu principal atrativo, pois os que dêle se utilizam acham-no então mais fácil de ser aplicado e justificado pela existência de dados substanciais, tangíveis, aparentemente mais objetivos. Entretanto, exige avaliadores bem treinados, é demorado e não é fácil selecionar e definir fatôres. Mas sua principal deficiência é que os fatôres só se aplicam a grupos de cargos relacionados e, de certa forma, comparáveis; em caso contrário, nem fatôres nem graus teriam significação.

\section{Escolha de Fatôres}

Inicialmente, baseada em análises e descrições de cargos, a comissão avaliadora estabelece os fatôres comuns a todos os cargos que, vamos supor, sejam os mesmos anteriormente adotados, isto é, habilidade, esfôrço, responsabilidade e condições de trabalho, todos muito bem definidos. É sempre difícil conciliar fábrica e escritório como tendo os mesmos fatôres, nos seus diversos graus; por essa razão, freqüentemente, adotamse planos diferentes para um e outro.

Dentre os critérios, pelos quais tais fatôres são escolhidos, destacam-se os seguintes:

- fatôres sem importância não devem ser incluídos;

- os fatôres não devem se sobrepor, para não se anularem mùtuamente;

- os fatôres devem ser fáceis de ser definidos e compreendidos;

- os fatôres devem referir-se ao cargo e não ser relativos a pessoas; 
- os fatôres devem estar presentes em proporções diferentes para cargos diferentes, ou pouco adiantarão para distinguir um cargo de outro.

Considerando-se, em conjunto, os fatôres maiores e os subfatôres, ${ }^{3}$ seu número chega a variar nos diversos planos desde 3 até 35 , sendo 11 na maioria das emprêsas; a variação do número de fatôres adotados nesses planos é evidenciada pelos dados apresentados no Quadro 7.

Quadro 7: Método de Pontos

Número de Fatôres Adotados por Firmas Selecionadas

\begin{tabular}{lccccc}
\hline & $\begin{array}{c}\text { Habili- } \\
\text { dade }\end{array}$ & Esfôrço & $\begin{array}{c}\text { Respon- } \\
\text { sabilidade }\end{array}$ & $\begin{array}{c}\text { Condições de } \\
\text { Trabalho }\end{array}$ & Total \\
\hline General Foods & 7 & 1 & 2 & 0 & 10 \\
General Electric & 2 & 2 & 1 & 1 & 6 \\
Westinghouse Electric & 3 & 3 & 4 & 0 & 10 \\
$\begin{array}{l}\text { Baldwin Locomotive } \\
\text { Lockheed Aircraft }\end{array}$ & 4 & 2 & 3 & 3 & 12 \\
$\begin{array}{l}\text { Cheney Brothers } \\
\text { MeGlure, Haden \& }\end{array}$ & 1 & 2 & 1 & 2 & 7 \\
$\quad$ Ostman & 7 & 0 & 1 & 1 & 3 \\
\hline
\end{tabular}

Fonte Patton, John A. e Littlefield, C.L. Job Evaluation. Irwin, 1957, p. 120.

Apesar da grande variação no número de fatôres, de 3 a 24 , nota-se que algumas emprêsas não se utilizam do fator condições de trabalho, o que está se tornando uma tendência generalizada à medida que as condições de higiene e segurança melhoram progressivamente.

Embora o exemplo faça referência às emprêsas norte-americanas, a variação de fatôres ocorre também no Brasil.

\section{Graus e Pesos}

No método de pontos, além dos fatôres, usam-se sempre os graus, que são variações de pontos numa escala crescente, atribuídos dentro de cada fator (ou subfator), de acôrdo com a importância dêste em cada cargo. ${ }^{4}$ Certos planos dão o mesmo

3 Subfator, como está explicado no método de comparação de fatôres, refere-se à subdivisão de um fator maior. Por exemplo, o fator esfórço é subdividido em esfórço manual e esfórço mental.

4 Assim, exemplificando com o fator educação, para um grupo de técni$\cos , 01^{\circ}$ grau corresponderia à escola primária completada, o $2^{\circ}$ grau a 
número de graus para todos os fatôres. Outros variam, dando cinco graus para uns fatôres e oito para outros. Fatôres e graus são descritos com pormenores em um manual de avaliação.

Considerando que, conforme os cargos, certas características são bem mais importantes do que outras, geralmente atribuemse pesos diferentes aos diversos fatôres. Por exemplo, no caso de um ferramenteiro, a habilidade deve pesar mais, ao passo que, para um limpador de máquinas, as condições de trabalho necessàriamente são de maior pêso. Uma excessiva dependência a pesos tem a desvantagem de limitar a aplicação de um plano para sòmente um grupo específico de cargos.

\section{Etapas}

Resumindo, as etapas são:

1. Estabelecer e definir os fatôres comuns a todos os cargos.

2. Estabelecer os graus, em pontos e os pesos dos fatôres escolhidos.

3. De acôrdo com as descrições de cargos, preparar tabelas indicando o quanto cada cargo possui das características enumeradas, qualitativamente, e aplicando-se os pontos, quantitativamente.

4. Somar, para cada cargo, as leituras dos fatôres indicados.

5. Escalonar os cargos de acôrdo com os resultados obtidos.

6. Determinar o valor monetário para os diversos cargos.

O método de pontos está consubstanciado no Quado 8, que mostra a parte do manual da National Metal Trades Association, um dos mais conhecidos de todos. ${ }^{5}$ Apresenta onze fatôres e cinco graus; tanto os fatôres como os graus são bem definidos e há certos fatôres com maior pêso que outros; por exemplo, habilidade -50 , esfôrço -15 , responsabilidade -20 e condições

ginásio, o $3^{\circ}$ grau a colégio, o $4^{\circ}$ grau a curso superior e o $5^{\circ}$ grau a cursos de pós-graduação completados.

5 Esse plano consta de quase tôdas as publicações que tratam do assunto; por exemplo, MOORE, Franklin S. Manufacturing Management. Irwin, 1954 , p. 446 e 447 . Porém, dada a sua difusão, há perigo de distorções, quando utilizado, indiscriminadamente, sem alterações, para qualquer tipo de emprêsa. 
de trabalho - 15. Tanto os fatôres quanto os seus graus e os pesos são determinados pela comissão de avaliação, por julgamento pessoal, de modo que o procedimento não pode ser considerado como sendo totalmente científico. Êsse plano da NMTA tem sido, porém, amplamente adotado, apresentado avaliações que são condizentes com as idéias que supervisores têm das dificuldades relativas aos cargos.

Quadro 8: Método de Pontos

Pontos Atribuídos a Fatôres e a Graus (National Metal Trades Association)

HABILIDADE - PESO 50

1. Educação

2. Experiência

3. Iniciativa e Engenhosidade

$\begin{array}{rrrrr}14 & 28 & 42 & 56 & 70 \\ 22 & 44 & 66 & 88 & 110 \\ 14 & 28 & 42 & 56 & 70\end{array}$

ESFÓRÇO - PESO 15

4. Esfôrço Físico

5. Esfôrço Mental ou Visual

$\begin{array}{rrrrr}10 & 20 & 30 & 40 & 50 \\ 5 & 10 & 15 & 20 & 25\end{array}$

RESPONSABILIDADE - PESO 20

6. Equipamento, Processo

7. Material ou Produto

8. Segurança de Terceiros

9. Trabalho de Terceiros

$\begin{array}{lllll}\mathbf{5} & 10 & 15 & 20 & 25 \\ \mathbf{5} & 10 & 15 & 20 & 25 \\ \mathbf{5} & 10 & 15 & 20 & 25 \\ \mathbf{5} & 10 & 15 & 20 & 25\end{array}$

CONDIÇOES DE TRABALHO - PESO 15

10. Condições Gerais

11. Periculosidade

$\begin{array}{rrrrr}10 & 20 & 30 & 40 & 50 \\ 5 & 10 & 15 & 20 & 25\end{array}$

Note-se que os graus crescem em progressão aritmética constante para todos os fatôres. Em alguns planos, a progressão pode ser geométrica ou simplesmente uma progressão arbitràriamente escolhida. Exemplificando os vários tipos, temos:

progressão aritmética: $5-10-15-20-24-$ progressão geométrica: $5-10-20-40-80-$ progressão arbitrária: $5-10-25-40-60-$

A adoção de uma destas progrẹssões depende dos objetivos da avaliação. Assim, não se desejando nem um crescimento excessivamente lento dos graus que é dado por uma progressão arit- 
mética, nem uma superavaliação proporcionada aos graus mais altos pela progressão geométrica, procura-se estabelecer uma progressão arbitrária.

Embora, pela soma dos pontos obtidos por diversos cargos (conforme os seus graus nos diferentes fatôres) obtenha-se uma avaliação dos cargos em pontos, o que já é suficiente para comparação de uns com outros, é preciso que êsses pontos sejam transformados em valôres monetários, isto é, em cruzeiros/hora. ou mês.

\section{Curva Salarial ${ }^{6}$}

Costuma-se então fazer um diagrama de dispersão assim que os cargos foram avaliados e os pontos atribuídos. Tal diagrama expressa, à primeira vista, as posições relativas de estruturação de cargos e, de imediato, é possível constatar se ela foi bem executada ou se não está refletindo realìsticamente a situação salarial da emprêsa. No diagrama, os pontos são colocados nas abcissas e os salários reais nas ordenadas; determinase, a seguir, a linha de regressão (RT) que melhor se ajuste aos pontos dispersos, o que pode ser feito por simples inspeção ou, com maior precisão, pelo método estatístico dos mínimos quadrados.

Teremos, isoladamente, cargos pagos a menos $\left(X_{1}\right.$, abaixo da reta $\mathrm{RT}$ ) e cargos pagos a mais ( $\mathrm{X}^{1}$, acima da reta $\mathrm{RT}$ ) mas, a correção dêsses desvios é problema de fácil solução, uma vez determinada a reta. Qualquer salário, correspondente ao número de pontos de um cargo, é obtido levantando-se uma perpendicular do eixo dos $X$ (pontos), até encontrar a reta salarial, e daí até o eixo dos Y (cruzeiros/hora), paralelamente ao eixo dos X. Basta ler o salário na escala do eixo dos Y.

\section{Faixas Salariais}

O que ocorre, porém, é que, na maioria absoluta dos planos adotados não é conveniente estabelecer uma curva salarial, na

- Na Revista de Administração de Emprêsas, vol. 19, jun. de 1966, p. 75 a 94, o excelente artigo de SIEGFried HoYler e OSWALDo DE PAULA RAMOS, Análise de uma Curva de Salários, sôbre a determinação e a análise de uma curva de salários, compara dados de pesquisa salarial no mercado de trabalho com os dados obtidos internamente na emprêsa a partir de uma avaliação de cargos. 
qual, para cada total de pontos há um correspondente valor monetário único. Isto acarretaria um sem-número de salários diferentes, muitos dos quais diferindo por uma quantia mínima. Êsse aspecto dificultaria qualquer politica de remuneração que se tentasse, provocando uma série de queixas.

FIGURA 1: Método de Pontos - Determinação da Curva (Reta) Salarial

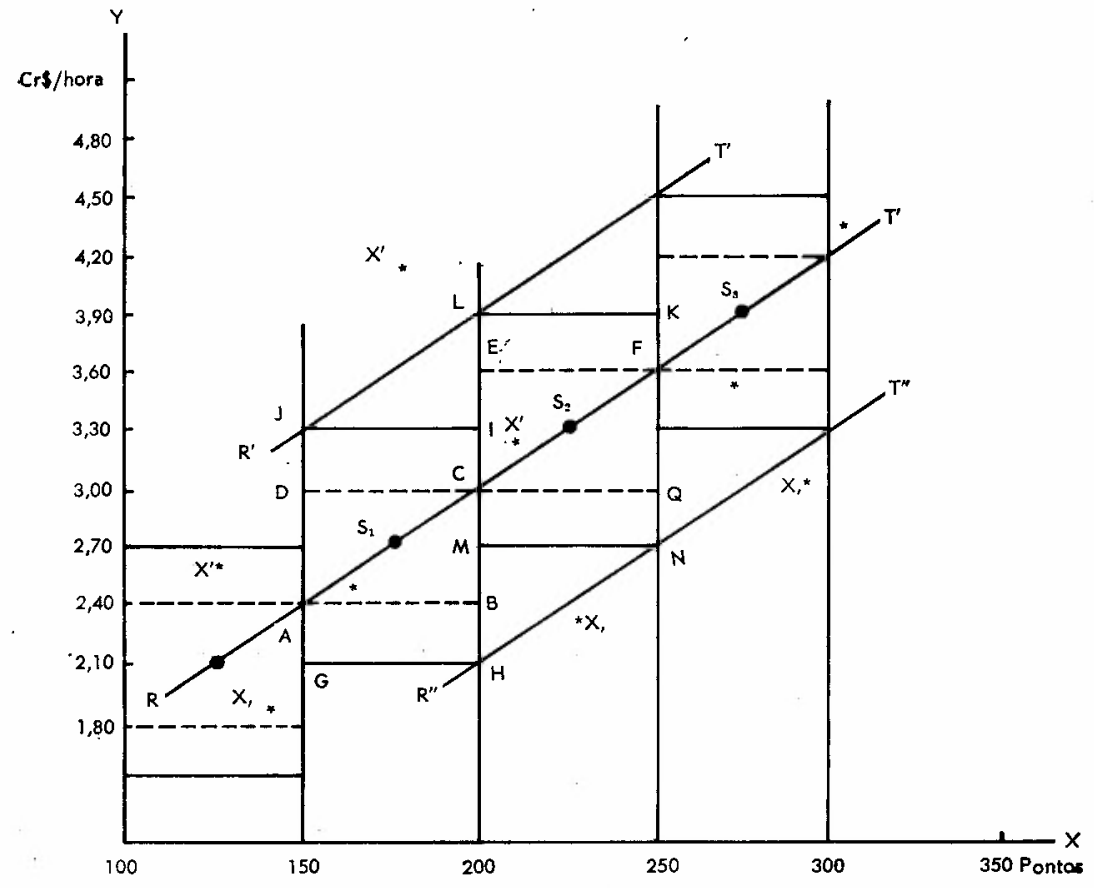

Estabelece-se, então, um certo número de classes, recebendo os cargos, dentro da mesma classe, um salário-base igual. Por exemplo, salário médio de $\mathrm{Cr} \$ 2,70 / \mathrm{h}\left(\mathrm{S}_{1}\right)$ para pontos de 150 a 199 , de $\operatorname{Cr} \$ 3,30 / \mathrm{h}\left(\mathrm{S}_{2}\right)$ para pontos de 200 a 249 e assim por diante (Quadro 9, coluna 2).

Para maior flexibilidade do plano, permitindo promoções por antiguiidade ou mérito dentro de cada classe de cargos (sem ser obrigatória a mudança para uma classe superior), adota-se, não um salário médio (coluna 2, do Quadro 9) para a classe, 
mas sim, uma faixa salarial (coluna 3, Quadro 9) desde um valor mínimo até um máximo. Por exemplo, em vez de $\mathrm{Cr} \$ 2,70 / \mathrm{h}$ para pontos de 150 a 199 , teríamos desde $\operatorname{Cr} \$ 2,70 / \mathrm{h}$ até $\ldots$. $\mathrm{Cr} \$ 3,00 / \mathrm{h}$. Na Figura 2, tal situação corresponderia ao retângulo $A B C D$. Observa-se que não há superposição com a classe imediatamente superior, formada pela retângulo CQFE, de .. Cr\$ 3,00 a $\mathrm{Cr} \$ 3,60$.

Quadro 9: Método de Pontos

Faixas Salariais

\begin{tabular}{cccc}
\hline $\begin{array}{c}\text { Classes } \\
\text { (em pontos) }\end{array}$ & $\begin{array}{c}\text { Base Salarial } \\
\text { Média }\end{array}$ & $\begin{array}{c}\text { Faiza Salarial (A) } \\
\text { sem Superposição }\end{array}$ & $\begin{array}{c}\text { Faixa Salarial (B) } \\
\text { com Superposição }\end{array}$ \\
\hline I $-100-149$ & $2,10 \mathrm{Cr} \$ / \mathrm{h}$ & $1,80-2,40 \mathrm{Cr} \$ / \mathrm{h}$ & $1,50-2,70 \mathrm{Cr} \$ / \mathrm{h}$ \\
II $-150-199$ & $2,70 \mathrm{Cr} \$ / \mathrm{h}$ & $2,40-3,00 \mathrm{Cr} \$ / \mathrm{h}$ & $2,10-3,30 \mathrm{Cr} \$ / \mathrm{h}$ \\
III $-200-249$ & $3,30 \mathrm{Cr} \$ / \mathrm{h}$ & $3,00-3,60 \mathrm{Cr} \$ / \mathrm{h}$ & $2,70-3,90 \mathrm{Cr} \$ / \mathrm{h}$ \\
IV $-250-299$ & $3,90 \mathrm{Cr} \$ / \mathrm{h}$ & $3,60-4,20 \mathrm{Cr} \$ / \mathrm{h}$ & $3,30-4,50 \mathrm{Cr} \$ / \mathrm{h}$ \\
\hline$\left(1 .{ }^{\mathrm{a}}\right)$ & $\left(2 .{ }^{\mathrm{a}}\right)$ & $\left(3 .{ }^{\mathrm{a}}\right)$ & $\left(4 . .^{\mathrm{a}}\right)$
\end{tabular}

No Quadro 9, quarta coluna, observa-se um caso de faixas salariais (B), com superposição de uma faixa sôbre outra, reconhecendo-se que cada classe possui cargos de valores variáveis de pontos, que podem atingir valôres até maiores que os da classe logo acima. A partir dessa superposição, constróem-se as retas R'T' e R'T', a primeira referente aos valôres máximos e a segunda aos valôres mínimos, respectivamente. Na Figura 1, seria o caso dos retângulos GHIJ e MNKL, onde há superposição em tôda a altura IM (correspondente a $\mathrm{Cr} \$ 0,60 / \mathrm{h}$ ) para as classes de 150-199 pontos e 200-249 pontos. Essa superposição não existe obrigatòriamente mas é estabelecida na maioria das vêzes, com o fim de reduzir uma excessiva rigidez salarial a que se chega quando não há superposição.

A superposição das faixas tem como vantagens principais no estabelecimento de uma política salarial o fato de:

1. elevar bastante o salário de alguém que o mereça, sem precisar haver transferência para cargo (classe) superior, onde talvez a pessoa não se sobressaia; 
2. permitir a transferência de pessoas para classes superiores sem aumentar demasiadamente os seus salários.

Estabelecidas as faixas e localizados dentro delas os cargos, é possível que alguns salários existentes excedam o máximo de sua classe e outros caiam abaixo do seu mínimo. Nesses casos, aumenta-se gradualmente os salários dos que são pagos a menos e aguarda-se que os pagos a mais sejam promovidos ou, se isto não fôr possível, que tenham seus salários acertados de alguma forma.

\section{A Avaliação de Cargos na Estrutura da Emprêsa}

O êxito do sistema de avaliação depende essencialmente do apoio da diretoria, do planejamento adequado do que se pretende fazer e da escolha de pessoal preparado para implantá-lo. Se não fôr bem executado, o melhor sistema planejado será inútil e até prejudicial. Diretrizes devem ser estabelecidas para orientar o trabalho que se vai empreender, facilitando a compreensão geral de todo o programa. Assim, por exemplo, deve ficar claro que o nível dos salários será maior, ou pelo menos igual aos pagos pela comunidade; que ninguém será prejudicado, pois aquêles que recebem menos do que o estabelecido serão ajustados; e que serão criadas classes para premiar tanto o mérito quanto a antigüidade.

Programas dessa natureza dificilmente podem prescindir da colaboração de especialistas no assunto. Mesmo que êssies sejam contratados fora da emprêsa, a execução da maior parte do trabalho dependerá do pessoal próprio, pois o que se deve ter em vista é a implantação de um programa permanente de avaliação de cargos, sem o que é melhor nem sequer começar.

Em emprêsas de maior porte, poder-se-ia pensar na organização de uma administração de salários, tal como a esquemàticamente reproduzida na Figura 2.

O que se destaca nesse organograma é que se alguém está precìpuamente encarregado da administração salarial como assessor do gerente de relações industriais, tendo como subordinados os encarregados das análises e descrições, avaliaçóes e pesquisas salariais. 
FIGURA 2: Organograma Parcial de Departamento de Relações Industriais

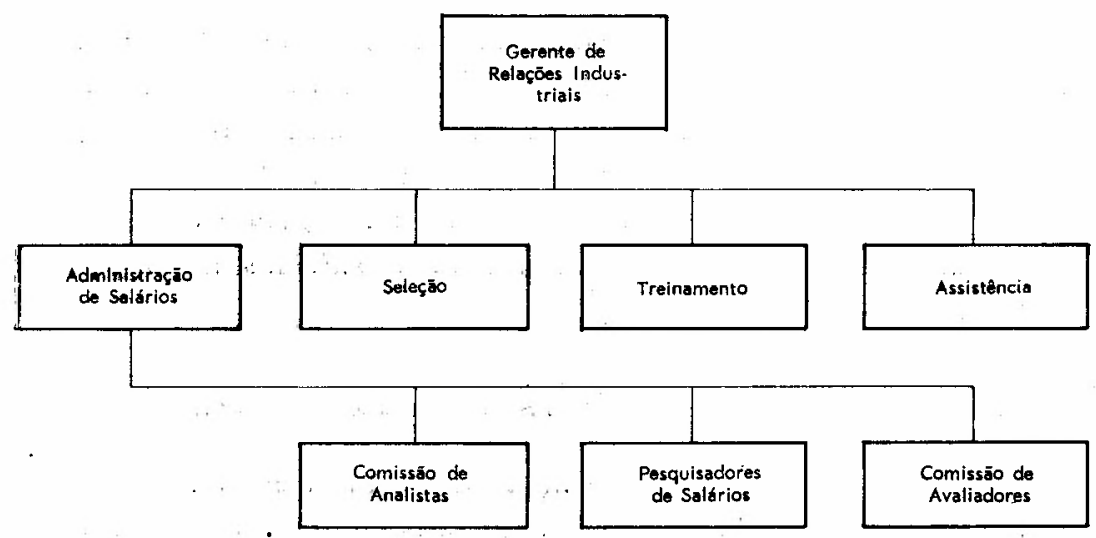

Em emprêsas menores, as comissões podem ser reduzidas a uma única, persistindo, porém, a necessidade de haver um assessor do gerente de pessoal, que seja responsável pelo programa de administração salarial. Das comissões, devem participar indivíduos qualificados, acatados e respeitados que conheçam bẹm a emprêsa, como por exemplo, mestres, encarregados de pessoal e empregados antigos. Essa participação deve ter como condições básicas o apoio da direção e a independência de ação. E quase certo, por outro lado, que vários dêsses indivíduos necessitem de treinamento antes de iniciarem as análises e avaliações.

Como deve ser escolhido, entre os métodos apresentados, o mais indicado para uma determinada emprêsa? A decisão é séria, pois, uma vez iniciado o trabalho, só com prejuízos, em tempo e dinheiro, êle poderá ser modificado.

Já foi dito que os dois últimos métodos apresentados, o de comparação de fatôres e o de pontos, se aplicam, de preferência a emprêsas de maior número de empregados e, os dois primeiros, o de escalonamento simples e o de classificação predeterminada, às menores. Para escolher um dêles, deve-se pesar bem as vantagens e desvantagens de cada um.

Poder-se-ia também estabelecer critérios adequados e comparar os diversos métodos. Considerando-se a objetividade, os me- 
lhores seriam, sem dúvida, o de pontos e o de comparação de fatôres, que tendem a ređuzir a proporções razoáveis o julgamento pessoal dos avaliadores. A flexibilidade do método, critério talvez menos importante, põe de lado o método de pontos, o mais inflexível dêles, em favor de qualquer um dos outros três, pois aquêle exige a determinação de fatôres muitas vêzes incomparáveis.

Um fator decisivo, geralmente, é a simplicidade ou a facilidade de compreensão do método; por êste critério, os mais indicados seriam os de escalonamento simples, classificação predeterminada e o de pontos. Outro critério ainda seria o de adaptabilidade à organização e, neste caso, qualquer um dêles, isoladamente ou em combinação com outros, ou modificado, poderá servir. $O$ principal é que a avaliação não seja reduzida a um processo aleatório, dependendo de simpatias pessoais e executada sem critério.

\section{Bibliografia}

American Management Association. The AMA Handbook of Wage and Salary Administration, Nova Iorque, 1950, cap. I-VI, IX-XI.

HempHILL, John K. Job Descriptions for Executives. Harvard Business Review, set.-out. de 1959, p. 55 a 67.

MOORE, Franklin G. Manufacturing Management. Irwin, 1954, cap. 21 a 25.

\section{CONCURSO DE ASSINATURAS DA RAE}

O Sr. Francisco Ruette, aluno do Curso de Pós-Graduação em Administração de Emprêsas da EAESP, foi o vencedor do re cente concurso promovido pela Escola.

O prêmio, conforme divulgamos em nosso último número, consiste em uma bôlsa de estudos na Escola de Administração de Emprêsas de São Paulo durante 2 semestres. 